\title{
Contraception as a risk factor for urinary tract infection in Port Harcourt, Nigeria: A case control study
}

\author{
Authors: \\ Paul O. Dienye ${ }^{1}$ \\ Precious K. Gbeneol ${ }^{1}$ \\ Affiliations: \\ ${ }^{1}$ Department of Family \\ Medicine, University of Port \\ Harcourt Teaching Hospital \\ (UPTH), Nigeria \\ Correspondence to: \\ Paul Dienye \\ Email: \\ pdienye@yahoo.com \\ Postal address: \\ Department of Family \\ Medicine, University of Port \\ Harcourt Teaching Hospital, \\ Nigeria \\ Dates: \\ Received: 22 June 2010 \\ Accepted: 14 Oct. 2010 \\ Published: 21 Apr. 2011 \\ How to cite this article: \\ Dienye PO, Gbeneol PK. \\ Contraception as a risk factor \\ for urinary tract infection \\ in Port Harcourt, Nigeria: \\ A case control study. Afr J \\ Prm Health Care Fam Med. \\ 2011;3(1), Art. \#207, 4 pages. \\ doi:10.4102/phcfm.v3i1.207
}

(C) 2011. The Authors. Licensee: OpenJournals Publishing. This work is licensed under the Creative Commons Attribution License.
Background: The concerted effort of government and donor agencies to limit fertility by the use of contraceptives has been reported in some studies to predispose to urinary tract infection (UTI). Similar studies have not been conducted in the General Outpatient Department (GOPD) of the University of Port Harcourt Teaching Hospital (UPTH).

Objectives: This study was aimed at assessing the role of contraceptives in the development of UTI amongst adult females attending the GOPD of UPTH.

Method: A case control study in which contraceptive users who attended the GOPD of the UPTH in four months, and an equal number of age-matched controls, were screened for UTI. The information obtained from them was entered into a specially designed pre-tested questionnaire for analysis. The results were analysed using SPSS version 14.

Results: A total of 150 contraceptive users and controls were evaluated. Their age range was $18-50$ years, with a mean of $27.8 \pm 5.3$ years. Most of the participants belonged to the lower socioeconomic classes. The combined prevalence of UTI amongst the contraceptive users and the controls was $23.7 \%$, with the contraceptive users at $35.3 \%$ and the controls at $12.0 \%$. The association of UTI with contraceptive use was statistically significant, with McNemar's $\chi^{2}=16.28, p=0.000$, odds ratio $(\mathrm{OR})=2.9,95 \%$ confidence interval $(\mathrm{CI})=1.7-5.3$, attributable risk $(\mathrm{AR})=23.3$, population attributable risk $(\mathrm{PAR})=11.7$. The users of barrier contraceptives were more predisposed to UTI $(\mathrm{OR}=17.30,95 \% \mathrm{CI}=7.49-39.96)$.

Conclusion: Contraceptive use is a significant risk factor for acquiring urinary tract infection, with the barrier methods being more predisposing. Health education for the hygienic and safe use of family planning methods will prevent long-term complications.

\section{Introduction}

One of the most serious problems that developing countries still have to solve is the rapid and uncontrolled increase in population. ${ }^{1}$ Although it has been estimated that the population of these countries, including Nigeria, will double in the next thirty years, ${ }^{2}$ there is a high incidence of unwanted pregnancies and abortion amongst sexually active Nigerian adolescents as a result of limited access to family planning services. ${ }^{3}$ To stem this trend, there are concerted efforts by government and donor agencies to limit fertility through the use of contraceptives. ${ }^{4}$

Worldwide, contraceptive use has increased substantially over the past two decades, with improvements in existing contraceptive methods and the development of several new, more effective and acceptable methods with fewer side effects. ${ }^{5}$ The efforts to improve contraceptive usage are commendable, but there has been increased concern about their safety. ${ }^{6}$ Many studies highlight the side effects and complications of different contraceptive methods. ${ }^{7,9,9,10}$ These studies mostly looked at hormonal contraceptives in which nausea, high blood pressure, varicose veins, menstrual disorders and breast cancer were reported. ${ }^{7}$

Previous studies identified urinary tract infection as a complication of contraceptive use. ${ }^{11,12}$ The predisposition of women to urinary tract infection (UTI), facilitated by the heavy colonisation of their lower vagina and periurethral area by uropathogenic bacteria, ${ }^{13,14}$ is aggravated by contraceptive use.

Even though UTI is a cause of morbidity, mortality and great economic loss, ${ }^{15,16}$ there is no known prospective study that has determined the role of contraceptives as a risk factor for urinary tract infection in the general outpatient department (GOPD) of the University of Port Harcourt Teaching Hospital (UPTH). This study is aimed at addressing this gap in knowledge. 


\section{Research significance}

Although UTI has been known as a cause of morbidity, mortality and great economic loss, there is no known prospective study to determine the predisposing role of contraceptives in the general outpatient department (GOPD) of the University of Port Harcourt Teaching Hospital. This study will therefore fill this gap in knowledge and justify the need to intensify health promotion and education on contraceptive use.

\section{Ethical considerations}

Ethical approval was obtained from the ethics committee of the University of Port Harcourt Teaching Hospital before the commencement of this study.

\section{Method \\ Design}

This was a matched case-control study in which consenting adult females (18-50 years old) who attended the GOPD in the UPTH, Port Harcourt within the four-month study period were recruited.

\section{Subject selection}

All consenting adult female contraceptive users within the age bracket of 18-50 years were recruited. Pregnant patients; patients with diabetes; patients experiencing vaginal discharge, dysuria, lower abdominal pains, loin pains; patients identifying with antimicrobial use during the last 14 days; patients who have participated in sexual intercourse within the last 24 hours and those hospitalised or catheterised during the four weeks before enrolment were excluded from the study.

\section{Sampling method}

One in every two qualified patients who presented to the GOPD, University of Port Harcourt Teaching Hospital was recruited into the study. Consecutive contraceptive users were recruited from amongst this group of patients by specifically asking them questions about their utilisation of contraceptives, sexual activity and frequency of sexual activity, as well as history of pain on micturation, loin pains and lower abdominal pains. For each contraceptive user identified, an age- and marital status-matched noncontraceptive user was selected randomly.

A total of 1504 pre-tested numbered intervieweradministered questionnaires were completed for all the recruited participants by the two researchers and two research assistants who were recruited as part of the study after being taught how to fill in the questionnaires and conduct the interviews. The questionnaire asked participants about their socio-demographic characteristics such as age, occupation and educational status, sexual history (activity and frequency) and types of contraceptives used, and symptoms of UTI such as dysuria and loin pain. Socioeconomic classes were determined using the method of Oyedeji. ${ }^{17}$ Cases and controls were clinically examined by the researchers. To maintain anonymity, the names of the participants were not written on the questionnaire but were coded serially. The participants were assured of confidentiality and informed that the information would only be used for scientific purposes.

The participants were requested and instructed to collect about $15 \mathrm{~mL}$ of 'clean catch' mid-stream urine in sterile bottles; this sample was sent to the microbiology laboratory of the teaching hospital for microscopy, culture and sensitivity. Those with positive bacterial culture in their urine were treated on the basis of the result.

\section{Analysing}

The data retrieved from the questionnaires were analysed using the Statistical Package for Social Sciences (SPSS) version 14 and the Microsoft Excel (MS) software program. The proportions of patients (prevalence) with urinary tract infections were calculated as a percentage. The degree of association of urinary tract infection with contraceptive use and the type of contraception were determined using McNemar's Chi-square test, odds ratio (OR) and attributable risk (AR). Tables were constructed to present the results. Statistical significance was set at the $95 \%$ confidence level (CI, confidence interval) or at a $p$-value of less than or equal to 0.05 ( $p$-value $\leq 0.05$ ).

\section{Results}

From the 1504 women recruited during the study period, $150(9.97 \%)$ contraceptive users were identified. The contraceptives used were barrier methods, Billing's method, implants, injectables, intrauterine contraceptive device (IUCD), oral contraceptives, bilateral tubal ligation (BTL) and the withdrawal method. The barrier contraceptives used included male condoms [47 (82.46\%)], female condoms [3 (5.26\%)], foaming spermicide tablets [6 (10.53\%)], and the diaphragm [1 (1.75\%)]. The participants' ages ranged from $18-50$ years, with a mean age of $27.8 \pm 5.3$ years. The majority of the participants [63 (42.0\%)] belonged to the 21-30-year age group, and $117(78 \%)$ were married (Table 1$)$. It was found that $35.3 \%$ of the contraceptive users and $12.0 \%$ of the controls had UTI. There was a significant association of UTI with contraceptive use (McNemar's $\chi^{2}=16.28, p=0.000$, $\mathrm{OR}=2.9,95 \% \mathrm{CI}=1.7-5.3, \mathrm{AR}=23.3, \mathrm{PAR}=11.7$ ) (Table 2). The prevalence of UTI in the various socioeconomic classes was similar amongst the contraceptive users, but amongst the controls it was higher in classes $2-4$. The differences in the prevalence amongst the contraceptive users and the controls were statistically significant in all the groups, apart from classes 3 and $4(p<0.05)$ (Table 3$)$. The prevalence of UTI amongst the barrier contraceptive users was $71.9 \%$ and they were found to be more predisposed to UTI (OR = 17.30, $95 \%$ CI $=7.49$ - 39.96). The association between the type of contraceptive and UTI was statistically significant $(p=0.000)$ (see Table 4). 
TABLE 1: Distribution of contraceptive users and controls by age and marital status $(n=150)$

\begin{tabular}{lccccc}
\hline Distribution & \multicolumn{2}{c}{ Participants } & & \multicolumn{2}{c}{ Controls } \\
\cline { 2 - 3 } \cline { 5 - 6 } & $\boldsymbol{n}$ & $\%$ & & $\boldsymbol{n}$ & $\%$ \\
\hline Age range & 32 & 21.3 & & 32 & 21.3 \\
$\leq 20$ & 63 & 42.0 & & 63 & 42.0 \\
$21-30$ & 45 & 30.0 & & 45 & 30.0 \\
$31-40$ & 10 & 6.7 & & 10 & 6.7 \\
$41-50$ & & & & & \\
Marital status & 26 & 17.3 & & 26 & 17.3 \\
Single & 117 & 78.0 & & 117 & 78.0 \\
Married & 7 & 4.7 & & 7 & 4.7 \\
Widows & & & & & \\
\hline
\end{tabular}

TABLE 2: The prevalence of urinary tract infection amongst contraceptive users and the controls.

\begin{tabular}{|c|c|c|c|c|}
\hline \multirow[t]{2}{*}{ UTI status } & \multicolumn{2}{|c|}{ Participants } & \multicolumn{2}{|c|}{ Controls } \\
\hline & $n$ & $\%$ & $n$ & $\%$ \\
\hline Infection & 53 & 35.3 & 18 & 12.0 \\
\hline No infection & 97 & 64.7 & 132 & 82.0 \\
\hline Total & 150 & 100 & 150 & 100 \\
\hline
\end{tabular}

UTI, urinary tract infection.

McNemar's $\chi^{2}=16.28 ; p=0.000 ;$ odds ratio $=2.9 ; 95 \%$ confidence interval $=1.7-5.3$ attributable risk proportion $=23.3$; population attributable risk proportion $=11.7$.

\section{Discussion}

This study discovered a predominance of participants within the 16-45-year age bracket and those that were married amongst the contraceptive users. This predominance can be explained by the fact that this is the reproductive age bracket, when sexual activity is a norm. The reduced number of contraceptive users in the older age group could be explained by the fact that, with aging, there is a decline in ovarian hormonal secretion during the menopausal transition, which may alter libido, sexual response and functioning, ${ }^{18,19,20}$ with concomitant loss of interest in contraception.

The widely used indicators of socioeconomic status include education, occupational status and income. ${ }^{17}$ The contraceptive users in the low socioeconomic classes may be more prone to UTI due to the interplay of these social indicators. ${ }^{15,21}$ The expected trend of a high prevalence of UTI in the lower socioeconomic classes was not observed in our study population, and this is not in agreement with previous reports. ${ }^{22,23}$ It could be explained by the fact that the social indicators did not alter our participants' exposure to the factors responsible for UTI amongst contraceptive users. The relevance of this finding is that, in planning health promotional programmes, equal attention should be given to people in all the socioeconomic classes.
The overall prevalence of UTI (35.3\%) amongst the contraceptive users was high. There was about a threefold increased risk of the development of urinary tract infection amongst patients who were on contraceptives compared to non-users. This finding is consistent with that of other researchers. ${ }^{24,25,26,27}$ The fact that the participants were asymptomatic makes it an unacceptable public health problem that calls for urgent intervention, in terms of health education and promotion and encouragement of the use of contraceptive methods that carry lesser risks of urinary tract infection.

The high prevalence of UTI amongst the barrier contraceptive users in this study is in agreement with earlier studies that reported high prevalence of UTI amongst patients who used both the diaphragm with spermicide and spermicidecoated condoms. ${ }^{28,29,30,31,32,33}$ Exposure to spermicides alone has been reported to increase the risk of vaginal colonisation and bacteriuria with Escherichia coli (E. coli), but not to the degree seen with the use of a diaphragm and spermicide..$^{25}$ In the population studied here, the use of diaphragm and spermicide in the form of foaming tablets was not popular, hence the low prevalence of their usage. The high prevalence of UTI amongst the barrier contraceptive users may therefore emanate from unhygienic conditions during application of the condom, ${ }^{29}$ which was the commonest barrier method used in this study. Secondly, unlubricated condoms may abrade the vaginal wall and make it vulnerable to infections. Thirdly, it has been suggested that the users of the barrier methods are likely to have increased vaginal fluid $\mathrm{pH}$, alterations in normal vaginal flora, and increased rates of introital colonisation with $E$. coli-all associated with UTI. ${ }^{28}$

The part played by the hormonal contraceptives in the aetiology of UTI was to a lesser degree than that reported in a study by Ziaei and colleagues. ${ }^{26}$ The effects of progesterone on muscle tone, peristalsis of the ureters and also on the urinary vasculature may account for the UTI in women who use hormonal contraceptives. ${ }^{25}$

\section{Conclusion}

On the basis of the findings of this study it can be concluded that contraceptive use is a significant risk factor for acquiring urinary tract infection, with the barrier methods being more predisposing. This warrants greater attention being paid to the reproductive health needs of the women, and health education for the hygienic or safe use of family planning methods. Women who use the barrier methods could

TABLE 3: Distribution of urinary tract infection amongst the participants from different socioeconomic classes.

\begin{tabular}{|c|c|c|c|c|c|c|c|c|c|}
\hline \multirow[t]{2}{*}{ Socioeconomic class } & \multicolumn{2}{|c|}{ Participants } & \multicolumn{2}{|c|}{ UTI } & \multicolumn{2}{|c|}{ Controls } & \multicolumn{2}{|c|}{ UTI } & \multirow[t]{2}{*}{$p$-value } \\
\hline & $n$ & $\%$ & $n$ & $\%$ & $n$ & $\%$ & $n$ & $\%$ & \\
\hline 1 & 10 & 6.7 & 3 & 30.0 & 6 & 4.0 & 0 & 0.0 & $<0.01^{\text {a }}$ \\
\hline 2 & 19 & 12.7 & 7 & 36.8 & 5 & 3.3 & 1 & 20.0 & $0.03^{\mathrm{a}}$ \\
\hline 3 & 36 & 24.0 & 13 & 36.1 & 11 & 7.3 & 3 & 27.3 & 0.20 \\
\hline 4 & 33 & 22.0 & 9 & 27.3 & 38 & 25.3 & 8 & 21.1 & 0.37 \\
\hline 5 & 52 & 34.7 & 21 & 40.4 & 90 & 60.0 & 6 & 6.7 & $<0.01^{\mathrm{a}}$ \\
\hline Total & 150 & - & 53 & - & 150 & - & 18 & - & - \\
\hline
\end{tabular}

UTI, urinary tract infection.

a $\chi^{2}$ statistically significant 
TABLE 4: Association of urinary tract infection with type of contraceptive.

\begin{tabular}{lcccccc}
\hline \multirow{2}{*}{ Type } & \multicolumn{2}{c}{ Infection } & & \multicolumn{2}{c}{ No infection } & \multirow{2}{*}{ Total } \\
\cline { 2 - 3 } & $\boldsymbol{n}$ & $\boldsymbol{\%}$ & & $\boldsymbol{n}$ & $\boldsymbol{\%}$ & \\
\hline Barrier contraceptives & 41 & 71.9 & & 16 & 21.8 & 57 \\
Hormone contraceptive & 12 & 12.9 & & 81 & 87.1 & 93 \\
\hline Total & 53 & $\mathbf{3 5 . 3}$ & & $\mathbf{9 7}$ & $\mathbf{6 4 . 7}$ & $\mathbf{1 5 0}$ \\
\hline
\end{tabular}

Values are given as $\chi^{2}=53.8 ; p=0.000$; odds ratio $=17.30 ; 95 \%$ confidence interval $=7.49-39.96$.

TABLE 5: Estimates of various statistical parameters.

\begin{tabular}{lcccc}
\hline Statistical parameters & \multicolumn{5}{c}{ Estimates } \\
\cline { 2 - 5 } & $\%$ & $p$-value & Ratio & Proportion \\
\hline Prevalence of UTI & & & & \\
Amongst contraceptive users & 35.3 & - & - & - \\
Amongst non-contraceptive users & 12.0 & - & - & - \\
McNemar's Chi-square & - & $16.28^{*}$ & - & - \\
Odds ratio and 95\% confidence interval & - & - & $2.9(1.7-5.3)$ & - \\
ARP & - & - & - & 0.66 \\
PARP & - & - & - & 0.49 \\
\hline
\end{tabular}

UTI, urinary tract infection; ARP, attributable risk proportion; PARP, population attributable risk proportion.

$*, p=0.000$

be advised to consider alternative methods, such as oral contraceptives. It is important, however, that the advantages of a method in terms of UTI prevention be balanced against the loss of protection against sexually transmitted diseases conferred by barrier methods.

\section{Acknowledgements Authors' contributions}

Paul O. Dienye designed the project, collected data and prepared the manuscript. Precious K. Gbeneol assisted in all the stages of preparation of the manuscript.

\section{References}

1. Rakel RE. The family physician. In: Rakel RE, editor. Textbook of Family Practice. 6th ed. London: W.B. Saunders Company, 2002; p. 3-18.

2. Yurdakul M, Vural G. Reasons for using traditional methods and role of nurses in family planning. Contraception. 2000;65:347-350. doi:10.1016/S00107824(01)00313-4

3. Feyisetan B, Pebley AR. Premarital sexuality in urban Nigeria. Studies in Family Planning. 1989;20(6):343-354. doi:10.2307/1966437, PMid:2623729

4. Mamadani $M$, Garner $P$, Harphan T, Campbell $O$. Fertility and contraceptive use in poor urban areas of developing countries. Health Policy and Planning use in poor urban areas of developing coun

5. Abasiattai AM. Current concepts in contraception. Nigerian Med J. 2006;15:364372.

6. Whelan EM. Compliance with contraceptive regimens. Stud Fam Plann 1974;5:349. doi:10.2307/1965188

7. Herold ES, Goodwin MS. Perceived side effects of oral contraceptives among adolescent girls. Can Med Assoc J. 1980;123(10):1022-1026. PMid:7448666, PMCid:1704998

8. Castle S. Factors influencing young Malians' reluctance to use hormonal contraceptives. Studies in Family Planning [serial online]. 2003; 34(3):186-199. Available from: http://www.ncbi.nlm.nih.gov/entrez/query.fcgi?linkbar=plain\&db=jo urnals\&term=0039-3665, doi:10.1111/j.1728-4465.2003.00186.x, PMid:14558321
9. Green J, Berrington de Gonzalez A, Sweetland S, et al. Risk factors for adenocarcinoma and squamous cell carcinoma of the cervix in women aged 20-44 years: the UK National Case-Control Study of Cervical Cancer. Brit J Cancer [serial online]. 2003; $89(11): 2078-2086$. Available from: http://wWw.ncbi.nlm.nih.gov/
entrez/query.fcgi?linkbar=plain\&db=journals\&term $=0007-0920$, doi:10.1038/ entrez/query.fcgi?linkbar=plain\&db=journals\&te
sj.bjc.6601296, PMid:14647141, PMCid:2376844

10. Mafuwa C, Djarova T, Matariva HT. Influence of combined oral contraceptives on the onset of CIN. Afr J Health. 2002;9(3-4):129-137.

11. Foxman B, Chi J-W. Health behavior and urinary tract infection in college-aged women. J Clin Epidemiol. 1990;43:329-337. doi:10.1016/0895-4356(90)90119-A

12. Foxman B, Geiger AM, Palin K, Gillespie B, Koopman JS. First-time urinary doi:10.1097/00001648-199503000-00013, PMid:7742403

13. Davison AM, Cumming AD, Swainson CP, Turner N. Diseases of the kidney and urinary system. In: Haslett C, Chilvers E, Hunter JA, Boon NA, editors. Davidson's principles and practice of medicine. 18th ed. London: Churchill Livingstone. 1999; p. 458-462.

14. Walter ES. Urinary tract infections and pyelonephritis. In: Braunwald $E$, Fauci $A$, Hauser S, Longo D, Kasper D, Jameson L, editors. Harrison's principles of internal medicine. 15th ed. New York: McGraw-Hill, 2001; p. 1620-1625.

15. Foxman B. Epidemiology of urinary tract infections: incidence, morbidity, and economic costs. Am J Med. 2002;113(1A):5. doi:10.1016/S0002-9343(02)01054-9

16. Nicolle LE, Harding GKM, Preiksaitis J, Ronald AR. The association of urinary tract infection with sexual intercourse. J Infect Dis. 1982;146:579-583. doi:10.1093/ infdis/146.5.579

17. Oyedeji GA. Socio-economic and cultural background of hospitalized children in Ilesha. Nig. J. Paediat. 1985;12:111-117.

18. Dennerstein L, Alexander JL, Kotz K. The menopause and sexual functioning: a review of the population-based studies. Annu Rev Sex Res. 2003;14:64-82. PMid:15287158

19. Bachmann GA, Leiblum SR. The impact of hormones on menopausal sexuality: a literature review. Menopause. 2004:11:120-130. doi:10.1097/01. GME.0000075502.60230.28, PMid:14716193

20. Palacios S, Tobar AC, Menendez C. Sexuality in the climacteric years. Maturitas. 2002;43(Suppl 1):S69-S77. doi:10.1016/S0378-5122(02)00150-0

21. Berkman L, Epstein AM. Beyond health care - socioeconomic status and health NEJM. 2008;358(23):2509-2510. doi:10.1056/NEJMe0802773, PMid:18525049

22. Remis RS, Gurwith MJ, Gurwith D, Hargrett-Bean NT, Layde PM. Risk factors for urinary tract infection. Am J Epidemiol. 1987;126(4):685-694. PMid:3631058

23. Patterson TF, Andriole VT. Bacteriuria in pregnancy. Infectious Disease Clinics of North America. 1987;1:807-822. PMid:3333660

24. Fihn SD, Latham RH, Roberts P, Running K, Stamm WE. Association between diaphragm use and urinary tract infection. JAMA. 1985;254:240-245. doi:10.1001/ jama.254.2.240, PMid:3999367

25. Hooton TM, Scholes D, Hughes JP, et al. A prospective study of risk factors for symptomatic urinary tract infection in young women. NEJM. 1996;335:468-474. doi:10.1056/NEJM199608153350703, PMid:8672152

26. Ziaei S, Ninavaei M, Faghihzadeh S. Urinary tract infection in the users of depotmedroxyprogesterone acetate. Acta Obstet Gynaecol Scand. 004;83(10):909-911.

27. Fallahian $M$, Mashhady E, Amiri Z. Asymptomatic bacteriuria in intrauterine devices. Urol J. 2005;2(3):157-159. PMid:17602420

28. Acton S, O'Meara YM. Urinary tract infection and contraceptive method. Irish Med J. 1997;90(5):176. PMid:9345824

29. Bhurt AW, Bozdar NM, Fikree FF. Prevalence and risk factors of presumptive urinary tract infection in a rural community. J Coll Physicians Surg Pak. 2000;10(1):16-19.

30. Strom BL, Collins M, West SL, Kreisberg J, Weller S. Sexual activity, contraceptive use, and other risk factors for symptomatic and asymptomatic bacteriuria: a casecontrol study. Ann Int Med. 1987;107:816-823. PMid:3688674

31. Foxman B, Frerichs RR. Epidemiology of urinary tract infection. I. Diaphragm use and sexual intercourse. Am J Public Health. 1985;75:1308-1313. doi:10.2105/ AJPH.75.11.1308, PMid:4051066, PMCid:1646718

32. Hooton TM, Roberts PL, Stamm WE. Effects of recent sexual activity and use of a diaphragm on vaginal microflora. Clin Infect Dis. 1994;19(2):274-278. doi:10.1093/clinids/19.2.274, PMid:7986899

33. Handley MA, Reingold AL, Shiboski S, Padian NS. Incidence of acute urinary tract infection in young women and use of male condoms with and without nonoxynol-9 spermicides. J Urol. 2003;170(1):338-339. 